\title{
ARQUEOLOGÍA, TURISMO Y COMUNIDADES ORIGINARIAS: UNA EXPERIENCIA EN NOR LÍPEZ (POTOSÍ, BOLIVIA)
}

\author{
ARCHAEOLOGY, TOURISM AND INDIGENOUS COMMUNITIES: \\ AN EXPERIENCE FROM NOR LÍPEZ (POTOSÍ, BOLIVIA)
}

\author{
Axel Nielsen*, Justino Calcina**, Bernardino Quispe***
}

\begin{abstract}
Durante la última década, las lagunas altoandinas de la Reserva Nacional de Fauna Andina "Eduardo Avaroa" (Sud Lípez, Departamento de Potosí) se han convertido en uno de los principales destinos turísticos de Bolivia. Estas excursiones, que parten de Uyuni o de San Pedro de Atacama y duran entre tres y cinco días, dejan escasos beneficios a la población rural, la que sin embargo sufre las consecuencias negativas del turismo sobre el medio ambiente, el patrimonio arqueológico y las relaciones comunitarias. En esta ponencia se discute una experiencia que se encuentran realizando desde 1996 las comunidades de Santiago K y Santiago Chuvica -ubicadas sobre la ruta que comunica Uyuni con la Reserva Avaroa- con un equipo de arqueólogos que está trabajando hace varios años en la región (Proyecto Arqueológico Altiplano Sur) a fin de desarrollar productos turísticos culturales que puedan insertarse en los circuitos locales, incluyendo la puesta en valor de aspectos seleccionados del patrimonio arqueológico. A través de estas acciones se busca aprovechar los resultados de la investigación científica para fortalecer la participación de los pobladores locales en los beneficios económicos y en la gestión del turismo, desarrollando al mismo tiempo estrategias para la conservación del patrimonio arqueológico regional.
\end{abstract}

Palabras claves: Comunidades indígenas, turismo cultural, Lípez, altiplano boliviano.

During the past decade, the high Andean lagoons of the National Reserve of Andean Fauna "Eduardo Avaroa" (Sud Lipez, Department of Potosí) have become one of the main touristic destinations in Bolivia. These tours, which leave from Uyuni or San Pedro de Atacama and last for three to five days, leave little benefit to the local rural population which, nevertheless, suffers the negative consequences of tourism on the environment, the archaeological heritage, and community relationships. This paper discusses an experience started in 1996 between the communities of Santiago Kand Santiago Chuvica-located on the route that communicates Uyuni with the Avaroa Reserve-and a team of archaeologists that have been working for several years in the region (Southern Altiplano Archaeological Project) with the goal of developing cultural touristic products that can be integrated into local tours, including selected components of the archaeological heritage. These actions seek to take advantage of the results of scientific research to strengthen the participation of local people in the economic benefits and administration of tourism, and simultaneously to develop strategies for the conservation of the archaeological resources of the area.

Key words: Aboriginal communities, cultural tourism, Lipez, Bolivian altiplano.

Durante la última década, el debate entre pueblos indígenas y arqueólogos en torno a los derechos sobre el patrimonio cultural arqueológico, incluyendo su control, administración e interpretación, ha cobrado singular intensidad en la subárea Centro Sur Andina. Esta discusión es producto -entre otros- de dos importantes procesos culturales que operan a escala mundial en estos tiempos y que es preciso considerar al analizar el tema y tomar posiciones.

El primero se refiere al resurgimiento (paradójico) de las identidades étnicas que acompaña al debilitamiento de los Estados nacionales en la era de la globalización. Regionalmente, esto se manifiesta en los movimientos de reivindicación de los pueblos originarios en países como Argentina y Chile, que desde el siglo XIX negaron su carácter multicultural -en especial sus raíces indígenascomo premisa para su constitución en estados-nación. Dentro de este proceso, que ya ha conquistado el reconocimiento legal de los pueblos aborígenes y sus derechos (inciso 17, artículo 75 de la Constitución Argentina de 1994; Convenio 169 de la OIT; Ley 19.253 de 1993 en Chile), los testimonios de

* Consejo Nacional de Investigaciones Científicas y Técnicas, Instituto Interdisciplinario Tilcara, Argentina. anielsen@imagine.com.ar

** Miembro de la Comunidad Santiago K, Bolivia.

*** Miembro de la Comunidad Santiago Chuvica, Bolivia. 
la historia indígena prehispánica adquieren especial relevancia como referentes objetivos de estas identidades resurgentes. ${ }^{1}$

El segundo proceso se relaciona a la formación de una cultura de élite híbrida y globalizada, que entre otras cosas se traduce en el auge de nuevas formas de turismo -conocidas como Turismo Cultural, Científico, Místico, Receptivo, Rural, Vivencial, Ecoturismo y Turismo de Aventura-que expresan diversas facetas de un interés creciente entre los sectores con mayores recursos, sobre todo de los países centrales, por acceder a experiencias directas de un mundo natural y cultural diverso y "prístino" que pareciera desvanecerse ante el avance de la modernidad. Estas actividades, que están experimentando un rápido crecimiento en el área andina, confieren al patrimonio cultural arqueológico un nuevo valor económico potencial. Frente al marcado aumento de las desigualdades sociales que caracteriza a esta época, muchas comunidades indígenas -que invariablemente forman parte de los sectores crecientemente marginados- ponen expectativas en utilizar su patrimonio arqueológico y cultural general para revertir esta situación de exclusión, reclamando sus derechos a participar de los beneficios económicos del turismo.

Por concurrir regularmente a los territorios indígenas a estudiar los testimonios del pasado, los arqueólogos se encuentran entre los primeros a quienes los pueblos originarios formulan estas legítimas demandas, que en última instancia están dirigidas a una sociedad y orden mayor del que -como científicos-forman parte. Los reclamos suelen incluir uno o más de los siguientes puntos:

1. Mantener los bienes arqueológicos en sus lugares (comunidades) de origen, devolviendo los que han sido extraídos anteriormente.

2. Informar a las comunidades los resultados de las investigaciones en un lenguaje accesible.

3. Dar participación a las comunidades en la gestión de su patrimonio arqueológico, ya sea con miras a la investigación, la explotación turística o el control del impacto generado por grandes obras.

4. Respetar las formas culturales locales de interpretar y manipular el patrimonio arqueológico, por ejemplo, tomando en cuenta el conocimiento tradicional del pasado o evitando la exhibición de restos humanos.
Algunos arqueólogos, particularmente aquellos que residen lejos de los territorios indígenas y que no han sido testigos de los rápidos cambios que acabamos de reseñar, se sorprenden ante tales cuestionamientos y los perciben como una amenaza a su profesión. Dada la falta de formación y recursos técnicos para garantizar la integridad de los sitios y materiales arqueológicos en las comunidades indígenas, muchos arqueólogos temen que si se da lugar a estas demandas la integridad del patrimonio y su potencial para la investigación científica podrían verse comprometidos.

La situación actual obliga a redefinir la relación entre arqueólogos y pueblos originarios, como así también el papel de la arqueología en los países del centro-sur andino. Este cambio -como todossuscita temores, pero promete importantes beneficios para todos. A los estudiosos del pasado y la cultura de los pueblos andinos les ofrece una oportunidad de intervenir en el desarrollo de los actuales procesos de cambio social a condición de abandonar sus torres de marfil; a los grupos indígenas les brinda una forma de enriquecer la comprensión de su propia historia y de potenciar la capacidad de su patrimonio para impulsar un desarrollo económico sustentable. Para que estas posibilidades puedan realizarse, sin embargo, es necesario que la relación entre arqueólogos y comunidades indígenas tome las características de un diálogo intercultural basado en el respeto mutuo. A partir de este diálogo podría forjarse una alianza que cada día parece ser más necesaria para defender el patrimonio cultural andino frente a la creciente amenaza de otras actividades, como el tráfico de antigüedades, la expansión de la infraestructura de servicios asociada con emprendimientos económicos de gran escala y el propio turismo sin regulación, entre otros.

En estas páginas comentamos la experiencia de un equipo de arqueólogos y dos comunidades originarias del altiplano sur de Bolivia que desde hace cinco años se encuentran trabajando para entablar una relación de este tipo. Esperamos que esta experiencia sea de utilidad a otros indígenas y arqueólogos que actualmente buscan nuevas formas de acercarse y trabajar juntos.

\section{La Coyuntura Regional en Lípez}

Lípez es el nombre con que se conoce al extremo sur del Altiplano boliviano (Departamento 
Potosí), comprendido entre el Salar de Uyuni y las fronteras internacionales con Chile y Argentina. Esta región permaneció hasta hace poco relativamente aislada de la infraestructura de comunicaciones asociada a las economías de mercado; durante gran parte del siglo XX se comportó como zona de expulsión demográfica hacia Argentina, Chile y los valles orientales andinos, tendencia que continúa en la actualidad. Sus habitantes, herederos de una rica tradición cultural que tiene sus orígenes en el pasado prehispánico, hablan actualmente el quechua y se dedican mayoritariamente al pastoreo de llamas y ovejas, combinado en algunos sectores con el cultivo de papa y quinua o actividades mineras. A diferencia de lo que sucede en el norte de Chile y noroeste de Argentina, toda la población de Lípez se encuentra organizada en comunidades indígenas desde hace -por lo menos- medio siglo. En toda la región se practica la propiedad comunitaria de la tierra y en muchas partes se conserva aún el sistema de autoridades originarias.

El rincón suroeste de esta región, cercano a la frontera tripartita con Chile y Argentina, con alturas mínimas superiores a los $4.300 \mathrm{msnm}$. y desprovisto de asentamientos permanentes, ofrece un paisaje de singular belleza, con lagunas multicolores (Laguna Colorada, Laguna Verde, Laguna Celeste), majestuosos volcanes (Uturuncu, Licancabur) y géiseres (Sol de Mañana). Gran parte de esta zona, junto con la cuenca superior del Río Quetena donde se asientan las comunidades de Quetana Grande y Quetena Chico, se encuentra comprendida en la Reserva Nacional de Fauna Andina "Eduardo Avaroa" (REA), creada en 1973 y ampliada en 1981 para alcanzar sus dimensiones actuales.

El flujo turístico hacia esta zona se inicia en la década de 1980, pero recién cobra auge en los años 90, cuando las llamadas "lagunas altoandinas" se convirtieron en el segundo lugar más frecuentado por el turismo en Bolivia, superadas sólo por la cuenca del Lago Titicaca. Actualmente visitan la REA casi 40.000 turistas por año, cantidad que se estima que continuará aumentando en los próximos años. Para apreciar el significado de estas cifras, hay que tener en cuenta que para llegar es necesario viajar entre 10 y 12 horas en vehículo liviano doble tracción por caminos en muy mal estado desde Uyuni, la ciudad boliviana más próxima, o 3 horas desde San Pedro de Atacama (Chi- le), y pernoctar en alojamientos que por lo general carecen de las comodidades mínimas.

El flujo de turistas a Lípez se origina principalmente en Uyuni (donde existen alrededor de 40 agencias que ofrecen excursiones a la zona) y en menor medida en San Pedro de Atacama. El tour prototípico se desarrolla en vehículos todo terreno que llevan entre cinco y siete pasajeros, un chofer que suele oficiar de guía y una cocinera. Saliendo de Uyuni, la duración del viaje es de tres a cinco días (Figura 1).

Día 1: Se cruza el Salar de Uyuni, almorzando en la Isla del Pescado, llegando por la tarde a San Juan (Nor Lípez). Alrededor de una decena de vecinos de este pueblo han construido alojamientos, consistentes en cuartos con techos de chapa, con 4 a 10 camas cada uno, y baños con toilettes y duchas con calefones de gas. Cada grupo lleva sus provisiones, las que son elaboradas por la cocinera del tour.

Día 2: Se cruza el Salar de Chiguana, dirigiéndose al sur a lo largo de la Cordillera Occidental, en forma paralela a la frontera con Chile. Se atraviesan varias cuencas lacustres de altura rodeadas por imponentes volcanes que ofrecen paisajes de singular belleza. Hacia el paralelo $22^{\circ}$ latitud sur, se ingresa al gran desierto de Siloli que marca el límite septentrional de la REA. Por la tarde se arriba a Laguna Colorada. Allí hay dos alojamientos; uno pertenece a un poblador de la zona, el otro es administrado por el servicio de Guardaparques de la Reserva.

Día 3: Se parte al amanecer para alcanzar los Géiseres de Sol de Mañana cuando alcanzan su mayor presión. Algunos grupos inician aquí el regreso, recorriendo con mayor detenimiento Laguna Colorada (donde existe una gran población de flamencos) y dirigiéndose desde allí hacia el noreste para llegar a Alota a descansar. Otros siguen hacia el sur, pasando los baños termales de Polques; quienes llegan con tiempo aprovechan para darse una rápida zambullida. Se atraviesa luego la vasta planicie volcánica de Pampa Jara para arribar a Laguna Verde, próxima al límite con Chile. Por la tarde se llega a Quetena. Tanto Quetena como Alota cuentan con alojamientos similares a los ya descritos. 


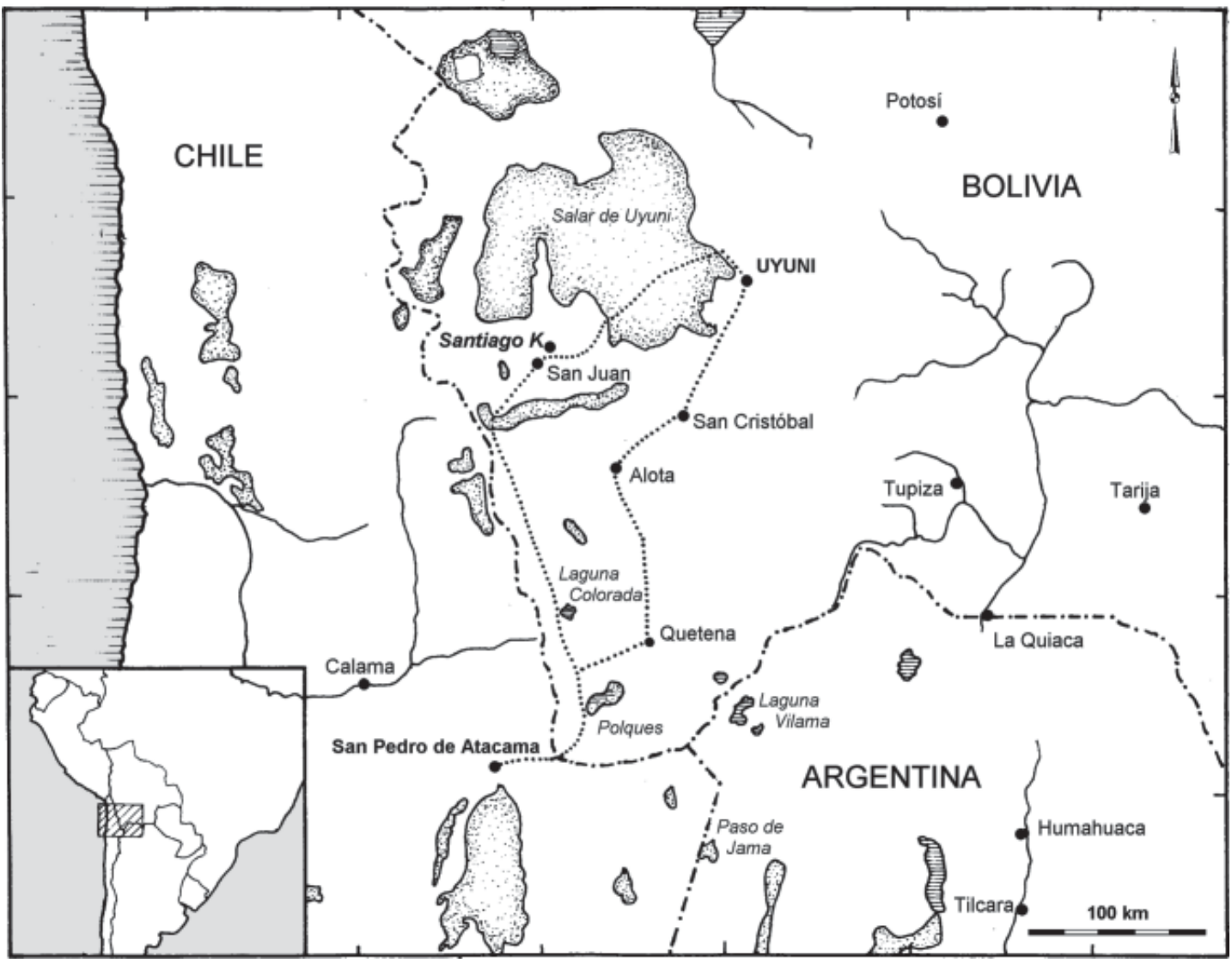

Figura 1. Circuito turístico en el Altiplano de Lípez, sur de Bolivia.

Tourist circuit in the highland of Lipez, southern Bolivia.

Día 4: Quienes pasaron la noche en Alota llegan a Uyuni temprano por la tarde. Quienes salen desde Quetena hacia Alota pueden visitar el pukara de Mallku (sobre el que no se ofrece información histórica alguna), llegando a Uyuni a última hora de la tarde.

Estos tours, que admiten algunas variantes menores, suelen costar alrededor de 100 dólares por persona en grupos de un mínimo de cuatro e incluyen alojamiento, comida, transporte y guía. Desde 1998 la Reserva cobra un pequeño derecho de ingreso. La mayor parte de quienes contratan estos servicios son jóvenes europeos y en menor medida norteamericanos e israelíes. Algunos de ellos vienen directamente a Uyuni para emprender este viaje; otros lo contratan en Potosí o La Paz.

Cabe destacar que el turismo en esta región se ha desarrollado como un fenómeno "espontáneo" (v.gr., sin planificación alguna y como resultado de iniciativas privadas aisladas) y "exógeno" (v.gr., no ha sido elegido por la población local, la que tampoco ha tenido oportunidad de intervenir en su diseño, desarrollo o administración). Los beneficios económicos de esta industria recaen en su mayor parte sobre las empresas de turismo de Uyuni y otros centros urbanos de Bolivia y Chile. Tal como está organizada actualmente la actividad, la única participación económica de la población se da a través del servicio de alojamiento que, como se señaló oportunamente, está concentrado en un número reducido de vecinos de tres o cuatro localidades.

Más compartidos están los perjuicios que ocasiona el turismo a las comunidades originarias y a su patrimonio. El interés que muestran los visitantes por el pasado local ha llevado a una depredación sistemática del patrimonio arqueológico. A veces los mismos turistas recogen fragmentos 
cerámicos o puntas de flecha como recuerdos de los sitios arqueológicos que visitan sin control alguno. Además los sitios arqueológicos a veces son elegidos como lugares para hacer picnic, agregando así la colecta de souvenirs como un atractivo más a la parada del almuerzo. En otros casos, son los propios pobladores quienes recogen objetos arqueológicos para la venta. De este modo, en muchos alojamientos el pasajero puede adquirir puntas de flecha que los niños recogen en el curso de sus labores de pastoreo. Algunos vecinos de una de las comunidades donde se alojan los turistas en tránsito han sido más creativos aún; advertidos del interés que despertaría en los turistas la existencia de un museo en la localidad, han puesto manos a la obra, extrayendo sin asesoramiento alguno todo tipo de piezas de los cementerios de chullpa de la zona, que hasta hace pocos años estaban excepcionalmente bien conservados. Hasta el año 2001 se exhibían en una sala cerca de San Juan vasijas, artefactos de metal, tejidos, momias, cestas, sogas y otra cantidad de objetos antiguos que han perdido irreversiblemente toda relación con su contexto y por lo tanto la mayor parte de su potencial para la investigación.

Otro tipo de impacto social se produce al interior de las comunidades que el turismo contacta en sus recorridos. Los vecinos que contaban con más recursos invirtieron en la construcción de alojamientos. La posibilidad de acceder a una entrada regular por este medio, ha resultado en un rápido crecimiento de las desigualdades en el seno de estas comunidades que, hasta hace pocos años, practicaban una economía casi totalmente al margen del dinero. A medida que se acentúan estas diferencias, los intereses de este sector y del resto de los comuneros vinculados a la producción rural de subsistencia difieren y hasta pueden tornarse contradictorios, socavando algunas de las pautas de relación básicas sobre las que descansa la reproducción material, social y cultural de la comunidad. De este modo, por ejemplo, algunos de los más beneficiados por la nueva industria comienzan a plantear la conveniencia de dividir las tierras de la comunidad entre sus miembros, dándoles así a cada uno la "libertad" para desarrollarse económicamente.

Las desigualdades y conflictos de intereses que acabamos de apuntar entre vecinos son más severos aún entre las comunidades que participan de la actividad turística y las que se encuentran al margen de ella. Más allá de la legitimidad de los reclamos de cada parte, las primeras cuentan con mayores recursos para resolver estos conflictos en su favor; por ejemplo, enviando representantes a $\mathrm{La}$ Paz o Potosí para llevar adelante gestiones ante autoridades nacionales y departamentales.

Por supuesto, no son los campesinos o las comunidades los responsables de estos problemas; su reacción es en gran medida una respuesta racional a las condiciones estructurales en que se ha desarrollado el turismo y a la imposibilidad de participar en la gestión del proceso. Así, por ejemplo, la enajenación del patrimonio arqueológico aparece como una estrategia eficaz a corto plazo -aunque obviamente insostenible a mediano plazo- para insertarse en un proceso económico del que están siendo excluidos. Las consecuencias de esta mercantilización del patrimonio para la cultura local son evidentemente perjudiciales, aunque actualmente difíciles de evaluar en todas sus implicaciones. Hasta hace una década, los pobladores de Lípez convivían con los testimonios de sus ancestros, que jugaban un papel activo en la reproducción de un mundo cargado de sentido. Hasta hace poco era común escuchar que "el abuelo" o "el chullpa" (refiriéndose por ejemplo a una momia semiexpuesta) cuidan los rastrojos o nos protegen de los intrusos. Hoy estos objetos se venden, como si fueran lo único de valor que la población local tiene para el extranjero y la única forma de ofrecérselo.

Una característica particularmente llamativa del turismo en Lípez es la ausencia de situaciones en las que se produzca un contacto significativo entre el visitante y la sociedad o cultura locales. Luego de cuatro días de fotografiar paisajes y observar aves, el turista retorna a Uyuni sin haber experimentado encuentros humanos significativos (salvo quizás con otros pasajeros en su grupo) y en una total ignorancia respecto a la identidad o la historia de las personas que lo alojaron o que avistó por la ventanilla de la camioneta. La experiencia no es menos alienante para los pobladores del lugar. Recordamos a un joven pastor de Sud Lípez que una vez nos preguntó con evidente preocupación si estábamos enterados de los planes de los "turistos", esa gente extraña que ya había instalado sus oficinas en Uyuni con el propósito de apoderarse de las tierras de Bolivia y expulsar de allí a sus actuales pobladores. 


\section{El Proyecto Lakaya}

En este contexto se inició en 1996 el Proyecto Lakaya (que literalmente significa "pueblo en ruinas"), un esfuerzo compartido entre un equipo de arqueólogos que trabaja en la región hace varios años (Proyecto Arqueológico Altiplano Sur) ${ }^{2}$ y miembros de las comunidades de Santiago K y Santiago Chuvica (Provincia Nor Lípez). Su objetivo es apoyar a las comunidades de la región para que puedan aprovechar su patrimonio arqueológico en función del turismo, favoreciendo su participación tanto en la gestión como en los beneficios económicos de esta actividad, mitigando simultáneamente sus impactos negativos para la naturaleza, la sociedad y la cultura locales.

El proyecto nació por iniciativa de algunos miembros de las comunidades, quienes al enterarse de las investigaciones que se estaban desarrollando, contactaron a los arqueólogos que se encontraba relevando el vasto asentamiento prehispánico de Lakaya, cercano a la ruta que une Uyuni con las lagunas altoandinas, manifestando su interés por participar en los estudios y solicitando asesoramiento para la puesta en valor de las ruinas. La colaboración que convenimos en desarrollar a partir de aquel momento hubiera sido similar a tantos otros proyectos de transferencia y difusión científica, de no haber mediado una acción espontánea de la propia comunidad, que desde el comienzo planteó al proyecto como un espacio de diálogo intercultural.

Al llegar a su término aquel viaje de 1996 en que se acordó la realización del proyecto, el Umachi -hombre de conocimiento encargado de velar por las "costumbres"- de Santiago convocó a los arqueólogos y a la comunidad en general a una reunión en la antigua plaza del sitio arqueológico sobre cuya puesta en valor se acordó trabajar. $\mathrm{Nu}$ merosos miembros de las dos comunidades llegaron allí vistiendo sus trajes tradicionales (axus, ponchos, chulos), encabezados por sus autoridades originarias portando sus bastones o Tata Reyes y demás emblemas de mando, quienes por varias horas obsequiaron a los arqueólogos -en quechuasus memorias sobre quiénes habían vivido antiguamente en el lugar (v.gr., los chullpa, la civilización anterior a la aparición del sol), relato que fue rematado con una ch'alla a los antiguos, invocando su protección para el desarrollo del proyecto. De este modo la comunidad recordaba a los arqueó- logos que, además del conocimiento que comenzaban a generar sobre el pasado de la zona con sus excavaciones, prospecciones y análisis, existía otro conocimiento aún vivo en la memoria de los ancianos. Mediante este acto sencillo pero imperativo, la comunidad reclamaba su derecho a participar en la construcción de su propia historia. A partir de entonces, se han realizado varias celebraciones de este tipo, a las que la comunidad ha agregado otras manifestaciones de su patrimonio cultural, como comidas, bailes, música, prácticas artesanales y representaciones teatrales.

Estos encuentros -podríamos llamarlos "rituales"- sintetizan el espíritu del proyecto, que en todas sus acciones busca respetar dos premisas fundamentales: autogestión e interculturalidad. La autogestión se traduce en la participación activa de las comunidades o sus representantes en todas las instancias de desarrollo del trabajo, desde la planificación y diseño a la investigación y ejecución de tareas, creación de organizaciones y evaluación de resultados. La interculturalidad reside en la búsqueda de un equilibrio entre las lógicas culturales de la comunidad local, del equipo técnico y de otros agentes que participan en el proceso (turistas, agencias de turismo, instituciones de financiamiento, etc.). Así se busca facilitar la apropiación efectiva de los resultados por parte de la comunidad, reducir al mínimo los desajustes entre necesidades y metas y aprovechar la propia dinámica de desarrollo del proyecto para fortalecer los mecanismos de organización ya existentes en las comunidades y la cultura local.

Hasta el momento el proyecto ha encarado tres líneas de acción: (1) puesta en valor de componentes seleccionados del patrimonio cultural (arqueológico, arquitectónico e inmaterial); (2) desarrollo de la infraestructura necesaria para recibir a los visitantes y otros mecanismos para canalizar la mayor cantidad posible de beneficios económicos del turismo hacia las comunidades, y (3) diseño de estrategias para prevenir y mitigar el impacto del turismo sobre la sociedad y cultura locales. En el futuro inmediato se espera abordar tareas de difusión y comercialización destinadas a insertar los nuevos productos desarrollados en los circuitos turísticos regionales (publicidad, acuerdos con operadores turísticos).

Las tareas de puesta en valor se inician con la selección, junto con la comunidad, de componen- 
tes del patrimonio aptos para su exhibición en función de su relevancia histórica y cultural y la factibilidad de su preservación. Hasta el momento se eligieron con este fin el sitio arqueológico de Lakaya y el sector antiguo del pueblo de Santiago, construido enteramente en piedra en el siglo XVIII sobre las ruinas del asentamiento Inka-Hispano Indígena de Chuquilla. Además, se estudia junto con la comunidad la posibilidad de poner en valor alguna fiesta o celebración tradicional y el desarrollo de un museo arqueológico. Con este fin, se inició la formación de una colección arqueológica a partir de donaciones de los vecinos de piezas que ya poseían como resultado de hallazgos fortuitos. Se realizaron además algunos rescates de objetos en lugares señalados por los miembros de la comunidad. La colección cuenta ya con más de un centenar de piezas, algunas de gran valor estético y significación arqueológica, las que se encuentran inventariadas y almacenadas en el corregimiento de Santiago K bajo custodia de las autoridades originarias.

La puesta en valor de Lakaya comenzó por la producción de la información necesaria para su interpretación, lo que implicó dos tipos de actividades. Por una parte, se dedicaron dos temporadas de investigación arqueológica al sitio; en ellas se levantó la planimetría completa, se excavaron dos viviendas de diferentes épocas y algunas estructuras asociadas a la plaza central. En todos estos trabajos participaron miembros de las comunidades, que tuvieron así oportunidad de familiarizarse con la lógica de producción del conocimiento científico, "desmitificando" esta forma de conocimiento y allanando así el diálogo intercultural. Por otra parte, se realizaron talleres de historia oral con los niños de las escuelas de ambas comunidades y otros con personas mayores, en los pueblos y en el propio sitio, relevando así aspectos del conocimiento tradicional sobre la historia de la región. En estos talleres se apeló a diversos medios para evocar y comunicar la información, incluyendo el relato tanto en quechua como en español, o la palabra escrita y el dibujo.

A partir de estas dos vertientes de información -el método científico y la tradición-se definió un sendero para recorrer el sitio que fue limpiado y señalizado mediante faenas comunitarias y se elaboró un folleto español-inglés que brinda los datos mínimos necesarios para la interpretación del re- corrido. Esta folletería, como todo el material interpretativo que se está elaborando en el proyecto (por ejemplo, síntesis de la historia regional), tiene una estructura "dialógica", que incorpora tanto aproximaciones tradicionales como científicas al conocimiento del pasado y la realidad local. En el caso de Lakaya, el folleto está ilustrado con fotos, planos y dibujos sobre los chullpa confeccionados por los niños de la escuela (Figura 2), mientras que los textos correspondientes a cada estación señalizada en el sendero se ofrecen en dos tipografías; una de ellas presenta información generada desde la lógica científica, la otra recoge algunos de los aportes locales recopilados durante los talleres de historia oral, como lo ejemplifica el siguiente extracto:

Cuentan que antiguamente, antes que existiera el sol, habitaba esta tierra la raza de los chullpa, gente fría, que vivía en la oscuridad o iluminada sólo por la luz de la luna y comía todo crudo. En aquel tiempo la llama hablaba con el hombre. Un día llegó el Inka trayendo el sol y el fuego. Heridos por la claridad y el calor, los chullpa trataron de protegerse refugiándose en sus casitas, que son como hornitos redondos, o en cuevas y grietas entre las peñas, donde aún se los encuentra "charquiados" junto a sus platitos y sus cositas, escondiendo sus rostros del sol. A partir de entonces, los chullpa se fueron extinguiendo, aunque dicen que hasta hace poco todavía quedaban algunos viejitos.

Lakaya -que en quechua significa "pueblo en ruinas"- es uno de los asentamientos precolombinos más importantes de Lípez, nombre con que se conoce al Altiplano boliviano al sur del Salar de Uyuni. El sitio cubre unas 7 hectáreas distribuidas en dos sectores principales: un reducto fortificado en lo alto y un poblado a sus pies. Fue habitado entre los siglos XII y XVII d.C., una época marcada por profundos cambios sociales y políticos, incluyendo la expansión y caída del imperio Inka y la conquista española de América. Recorrer Lakaya es una oportunidad de recordar este agitado período de la historia de los pueblos andinos. 


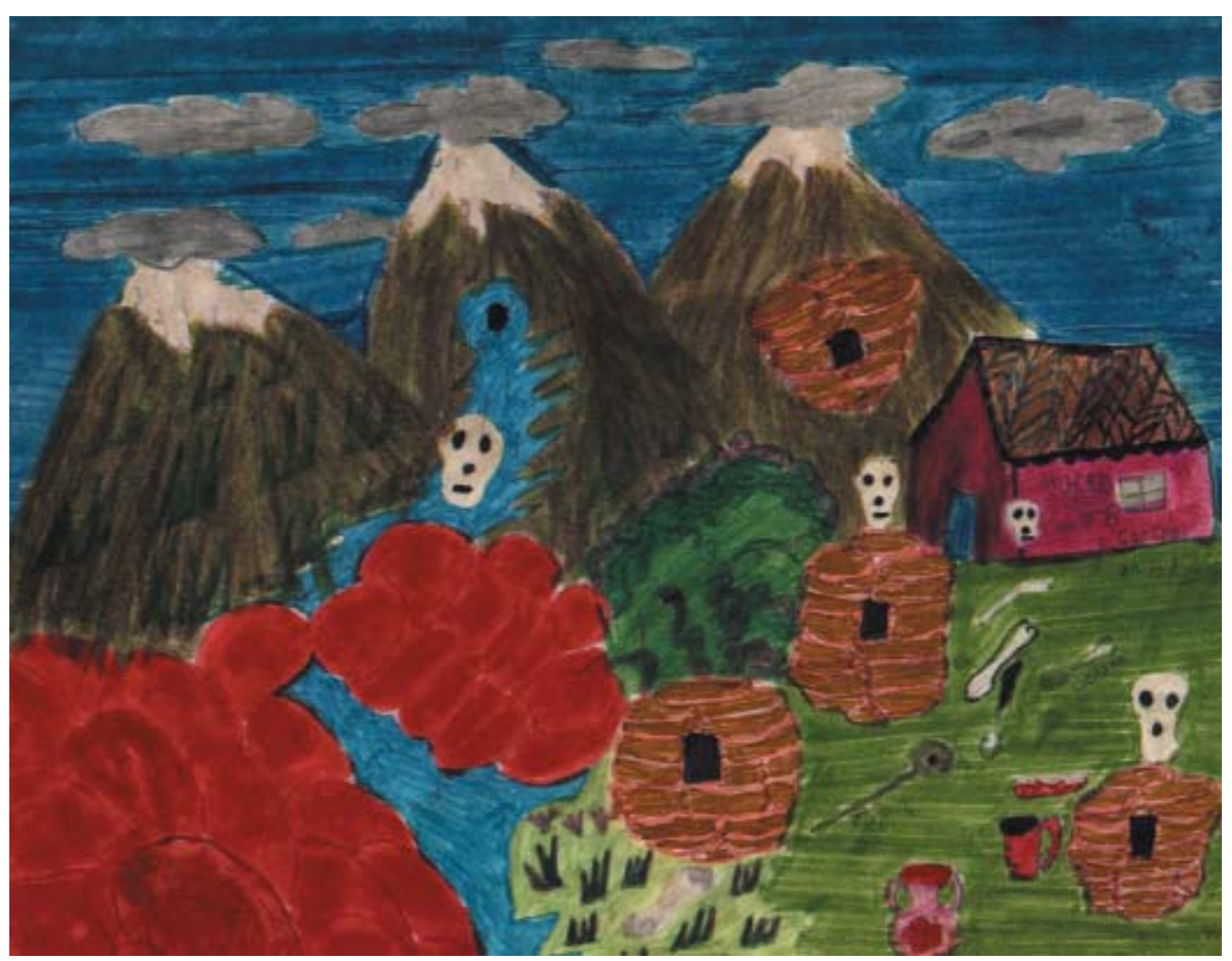

Figura 2: Uno de los dibujos que ilustra el folleto interpretativo de Lakaya (autora Maribel Mamaní Calcina, 10 años). One of the drawings that illustrates the brochure of the Lakaya project (drawing by Maribel Mamani Calcina, 10 years old).

La puesta en valor incluyó además la construcción mediante faenas comunitarias de la infraestructura necesaria para la recepción de visitantes: cerco, estacionamiento, caseta de recepción y baños, y la realización de un primer cursillo de guías en el que participó un centenar de personas. Para administrar los ingresos que generen las visitas al sitio se creó una comisión con representantes de ambas comunidades. Actualmente se está tramitando ante el gobierno nacional la declaratoria de Lakaya como Parque Arqueológico y la entrega oficial a las comunidades para su administración. El sitio abrió las puertas a los visitantes en el curso de 2002.

La segunda línea de trabajo concierne al desarrollo de mecanismos para canalizar la mayor cantidad posible de beneficios económicos del turismo a las comunidades. Esto incluye, entre otros, la construcción de un alojamiento comunitariamente administrado en Santiago K, talleres destinados a reactivar y fortalecer la producción artesanal local -especialmente tejidos en telar con lana de llama teñida con tintes naturales, a cargo de las comisiones de madres-y el desarrollo de otros productos para la venta (postales, otros textos sobre la historia regional). El alojamiento, que tendrá capacidad para unas 25 personas e incluirá un comedor, está siendo construido reciclando un antiguo local de la comunidad con materiales donados por diversos organismos y según diseño de arquitectos incorporados al proyecto que respetaron las pautas edilicias del sector antiguo del pueblo. Como en el caso de Lakaya, su inauguración estaba prevista para 2002.

La tercera línea de acción está referida a la prevención y mitigación del impacto que provocará el turismo sobre la sociedad y la cultura local. A tal efecto, se elaboró un plan de ordenamiento de la actividad en Santiago K -que restringe los ámbitos de circulación de los visitantes a fin de limi- 
tar la interferencia con la vida cotidiana de la comunidad- y un plan de control de residuos. Más allá de esto, la inminente llegada del turismo al lugar, los múltiples modos en que esto afectará su vida y las formas en que estos efectos podrían ser manejados, se han instalado como temas centrales de reflexión y discusión en la comunidad, siendo debatidos entre vecinos, en la escuela y en asambleas. En este sentido, creemos que el desenvolvimiento del propio proyecto, por su dinámica de diálogo intercultural, por actuar como espejo del patrimonio local (donde la práctica cultural en sí se asume como un bien que puede ser mostrado al otro) y por incorporar periódicamente un número limitado de extraños al lugar durante los últimos cinco años, ha operado eficazmente como oportunidad para que la propia comunidad elabore sus estrategias para manejar a los visitantes.

\section{Conclusión}

Hasta aquí hemos argumentado que la cooperación entre arqueólogos y comunidades originarias en torno a la administración y conservación del patrimonio arqueológico andino no sólo es posible y potencialmente beneficiosa para ambos, sino una condición necesaria para proteger ese patrimonio de los múltiples factores que actualmente lo amenazan. Para que esta alianza pueda concretarse es preciso que ambas partes se relacionen en un marco de respeto mutuo en el que se contemple la gestión compartida del patrimonio arqueológico y se acepte la legitimidad de múltiples formas culturales de abordarlo. Como ejemplo de esta posibilidad hemos descrito el caso de la colaboración establecida en los últimos años entre el Proyecto Arqueológico Altiplano Sur y algunas comunidades de Nor Lípez con el propósito de utilizar componentes seleccionados de su patrimonio arqueológico para contribuir al desarrollo económico local a través del turismo. Esperamos que este proyecto contribuya a facilitar su participación en esta actividad, aunque estamos conscientes de la complejidad del problema y lo limitada que es nuestra capacidad de intervenir en los procesos económicos y culturales involucrados. Confiamos, sin embargo, en que el diálogo intercultural establecido sirva para fortalecer la capacidad de las comunidades originarias para enfrentar lo diferente sin olvidar lo propio, y a los científicos sociales, para recordarles que la suya es sólo una forma cultural más de aproximarse a la historia y a la realidad.

\section{Notas}

1 Es importante destacar que el vínculo entre las comunidades indígenas y el patrimonio arqueológico es de naturaleza cultural, tiene su origen -y encuentra su legitimidaden la identificación consciente con un pasado y con el conjunto de restos materiales que dan testimonio de él, más allá de las relaciones biológicas de descendencia que puedan existir entre los individuos y las poblaciones creadoras de componentes específicos de ese patrimonio. Así lo ejemplifican los numerosos inmigrantes e hijos o nietos de inmigrantes de países vecinos que integran las comunidades indígenas recientemente constituidas en Argentina y que asumen el patrimonio arqueológico local como emblema de su identidad.

2 Las investigaciones arqueológicas del PAAS, así como las actividades de puesta en valor del patrimonio descritas en este trabajo, se vienen realizando a través de un convenio con el Viceministerio de Cultura de Bolivia y han contado con el apoyo de las autoridades de la Unidad Nacional de Arqueología (UNAR). Financiaron estos proyectos el Consejo Nacional de Investigaciones Científicas y Técnicas, la Universidad Nacional de Jujuy y la Fundación Levi Strauss, Argentina. 
